\title{
Experimental Verification of Light Electric Vehicle Charger Multiport Topology
}

\author{
Tanel Jalakas \\ Department of Electrical Engineering \\ Tallinn University of Technology \\ Tallinn, Estonia \\ tanel.jalakas@ttu.ee
}

\begin{abstract}
This paper describes a multiport topology based charging station for light electric vehicles, like electric-motor assisted bicycles (pedelec). The multiport topology allows energy flow control between the charging ports, alternative energy ports and the grid port. Every port can act bidirectionally, enabling easy integration of additional energy storages. Power flow regulation in a wide range with the multiport topology is not preferred due to high losses at phase shifts that exceed $40 \mathrm{deg}$. The topology is well suited for battery charging, as the required charging voltage change will be less than $30 \%$. To evaluate the multiport topology in the proposed application, a low power $250 \mathrm{~W}$ prototype charging station was designed, built and tested.
\end{abstract}

Keywords - Multiport converter, power, light electric vehicle battery charger, energy storage.

\section{INTRODUCTION}

Light electric vehicles are gaining popularity as the prices of energy carriers are rising and the mindset of the people is changing. Widespread use of light electric vehicles like electric-motor assisted bicycles (pedelec) creates a need for public charging stations with multiple charging ports and integrated alternative energy sources.

Traditionally, such devices are built by the use of a common DC-link along with dedicated uni- or bidirectional converters (battery charging, grid, energy storage and alternative energy source interfacing). The multiport topology is well suited for that task [1], [2], [3], [4]. The topology proposed has many advantages: every port allows bidirectional energy flow; energy flow can be easily controlled in a wide range by altering the phase angle $\varphi$ between the control signals of different ports; all ports are galvanically isolated. Light electric vehicles usually have either: 24,36 or $42 \mathrm{~V}$ lithium ion, lithium polymer or nickel metal hydride batteries. Typical capacity for such batteries is from 7 to $15 \mathrm{Ah}$. $24 \mathrm{~V}$ lithium ion battery voltage can drop to $21 \mathrm{~V}$ when empty. During charging it requires up to $29.4 \mathrm{~V}$. Typical safe charging current for $24 \mathrm{~V}$ pedelec batteries is $0.2 \mathrm{C}$ ( $\mathrm{C}$ represents the capacity of the battery in ampere-hours) (typically 1.5 to $3 \mathrm{~A}$ ) [5]. Those numbers show that the difference in the maximum and minimum values of the output voltage of the charging port is $29 \%$. This voltage regulation requirement is well suited for the multiport topology, because the efficiency of the topology drops when phase angles are large (Figure 1).

\author{
Janis Zakis \\ Institute of Industrial Electronics and Electrical Engineering \\ Riga Technical University \\ Riga, Latvia \\ janis.zakis@ieee.org
}

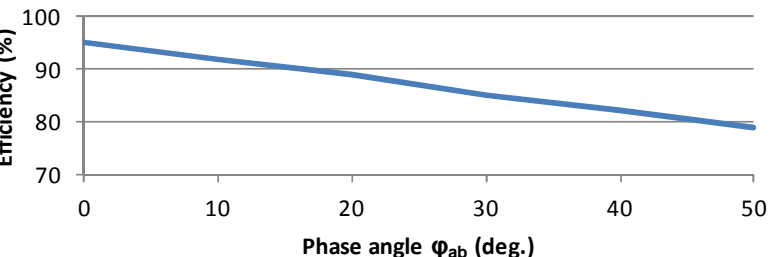

Figure 1. Experimentally verified phase angle to the efficiency characteristics of the multiport converter.

Figure 3 shows the principal schematic of a pedelec charging station for two vehicles with an additional solar energy port. $U_{\text {in }}$ is the rectified grid voltage. Voltage amplitude can be adjusted to a suitable level with the selection of a proper transformer primary to secondary turns ratio. A typical 60 cell $250 \mathrm{~W}$ solar panel can be connected to the solar port.

\section{CONTROL OF THE CHARgING STATION}

During the pedelec battery charge mode, the energy is directed from the grid and the solar port to the charger ports (Figure 2) (a). $U_{1}$ is the grid port input voltage (Figure 3), $U_{2}$ is 1 . Charger port output voltage, $U_{3}$ is second charger port output voltage, $U_{4}$ is the solar port input voltage. In Figure 2 (a) a simplified power flow model and (b) the vector diagram of a battery charger [2] are shown.

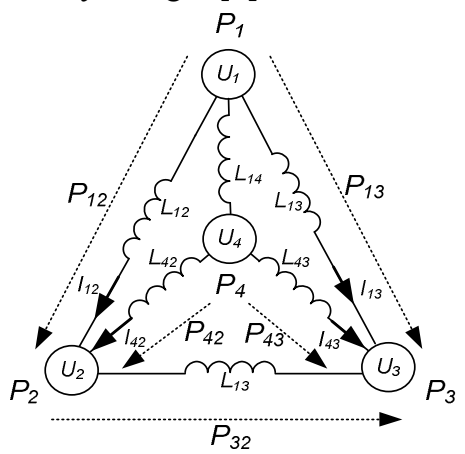

(a)

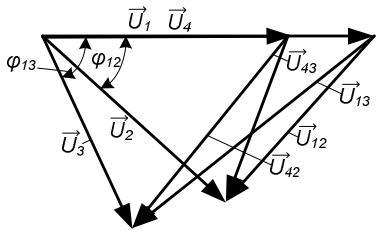

(b)
Figure 2 (a) Vector diagram and (b) energy flow model of an EV battery charger 


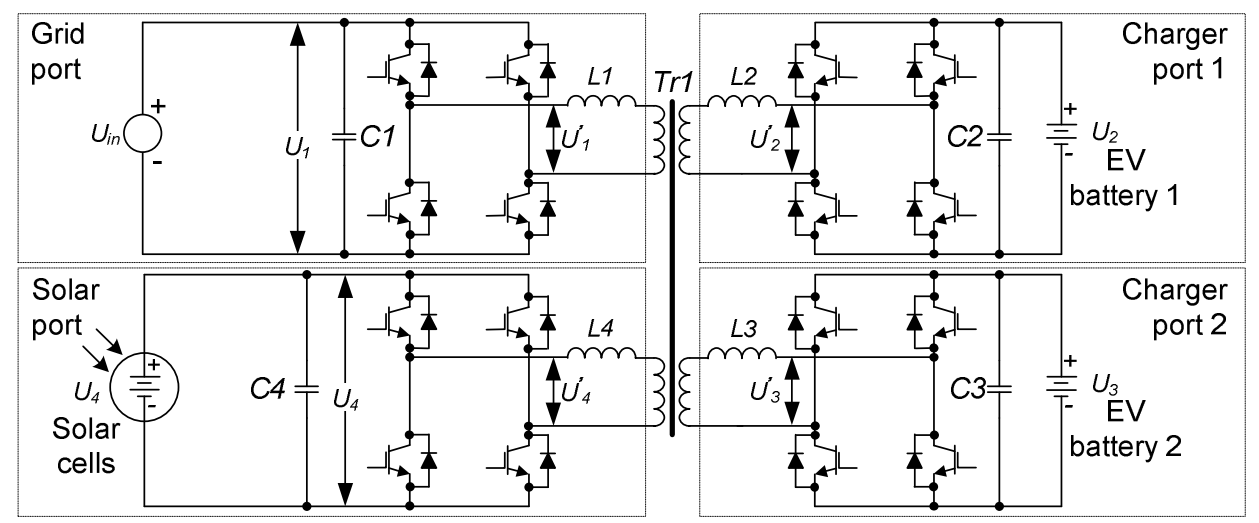

Figure 3. Light EV multiport charger with the solar energy port.

The allowed power flow $P_{b c}$ during the battery charging of a pedelec can be described as follows:

$P_{b c}=P_{12}+P_{13}+P_{42}+P_{43}$,

If only an allowed energy flow is from the grid port, then $P_{42}=P_{43}=0$. Power flows $P_{14}, P_{41}, P_{23}, P_{32}$ and $P_{31}$ are in current set-up unwanted and therefore must be prohibited by the use of phase angle limits and additional blocking diodes. Power flows $P_{21}, P_{24}, P_{31}, P_{34}$ are not possible as $U_{1}>U_{2}, U_{1}>$ $U_{3}$ and $U_{4}>U_{2}, U_{4}>U_{3}$.

Each power flow $P_{a b}$ between the two ports $a$ and $b$ is expressed by (large phase shift) [6], [7]:

$\varphi>\frac{\pi}{2}\left(1-D_{b}\right)^{2}$,

$P_{a b}=\frac{U_{a}}{D_{b} N_{T R} \omega L_{a b}}\left(\left(1-\frac{\varphi_{a b}}{\pi}\right)-\frac{\pi}{4}\left(1-D_{b}\right)^{2}\right)$,

or by (small phase angle) [6]:

$-\frac{\pi}{2}\left(1-D_{b}\right)^{2} \leq \varphi \leq \frac{\pi}{2}\left(1-D_{b}\right)^{2}$,

$P_{a b}=\frac{U_{a}^{2}}{\omega L_{a b}} \varphi$

$D_{b}=\frac{N_{T R} U_{a}}{U_{b}}$.

where $D_{b}$ is the duty cycle of respective port voltage waveform, $U_{a}$ and $U_{b}$ are port voltages, $L_{a b}$ is inductance between the ports (transformer leakage inductance), $\omega$ is angular frequency, $N_{T R}$ is the transformer's turns ratio and $\varphi_{a b}$ is the phase angle between the port voltages.

\section{EXPERIMENTAL RESULTS}

For experimental verification, a prototype converter with four identical ports was built. The first port was supplied with rectified and lowered DC voltage $U_{l}$ from the grid. Ports 2 and 3 were charging ports. Port 4 was used to supply the charging ports from an alternative energy source like a solar array. Figure 4 shows the experimental battery charger.

Light EV batteries to be charged were chosen Li-Ion $24 \mathrm{~V}, 10$ Ah batteries with 7 series connected $3.7 \mathrm{~V}$ cells. Charging voltage of specified cells ranges from $3 \mathrm{~V}$ (empty) to $4.2 \mathrm{~V}$ (max. charging voltage). Therefore, the whole battery pack requires a charging voltage from $21 \mathrm{~V}$ to $29.4 \mathrm{~V}$.

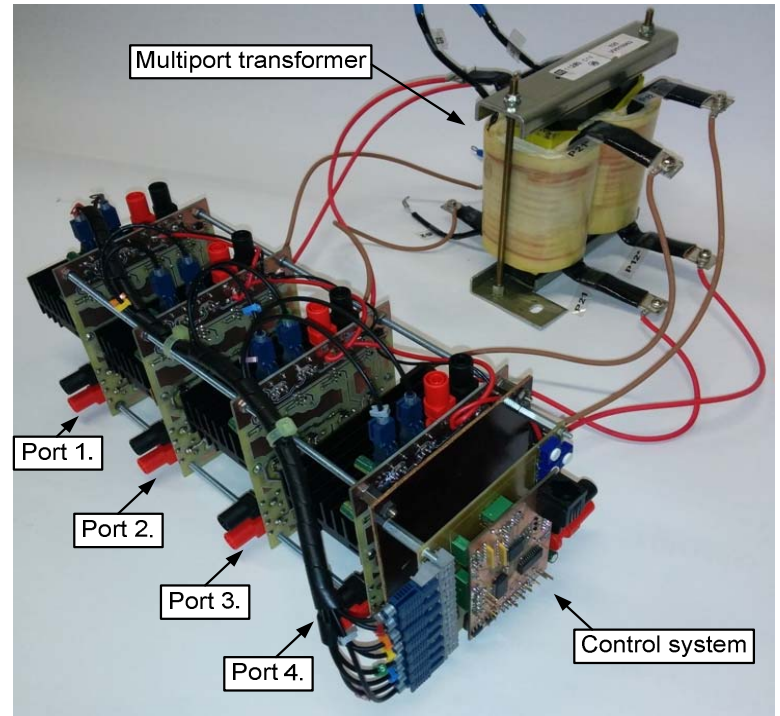

Figure 4. Experimental battery charger set-up.

Parameters of the experimental battery charger are listed in Table 1.

TABLE 1

PARAMETERS OF THE EXPERIMENTAL SET-UP

\begin{tabular}{|c|c|c|}
\hline Symbol & Parameter & Value \\
\hline$U_{\text {grid }}$ & Input voltage (RMS) & $230 \mathrm{~V}, 50 \mathrm{~Hz}$ \\
\hline$U_{I}$ & Grid port DC-link voltage & $33 \mathrm{~V} \mathrm{DC}$ \\
\hline$\overline{U_{2}}$ & $\begin{array}{l}\text { Renewable energy port } \\
\text { DC-link voltage }\end{array}$ & $42 \mathrm{~V} \mathrm{DC}$ \\
\hline$\overline{U_{3}}=U_{4}$ & $\begin{array}{l}\text { EV battery max. charging } \\
\text { voltage (battery full) }\end{array}$ & $29.4 \mathrm{~V} \mathrm{DC}$ \\
\hline$U_{3 \min }=U_{4 \min }$ & $\begin{array}{l}\text { Storage and EV battery } \\
\text { min. charging voltage } \\
\text { (battery empty) }\end{array}$ & $21 \mathrm{~V} \mathrm{DC}$ \\
\hline$L_{l}=L_{2}$ & $\begin{array}{l}\text { Stray inductance of } \\
\text { multiport transformer }\end{array}$ & $10 \mu \mathrm{H}$ \\
\hline$L_{3}=L_{4}$ & $\begin{array}{l}\text { Stray inductance of } \\
\text { multiport transformer }\end{array}$ & $80 \mu \mathrm{H}$ \\
\hline$L_{11}=L_{12}$ & Port 1 and port 2 inductors & $30 \mu \mathrm{H}$ \\
\hline$C_{1}=C_{2}=C_{3}=C_{4}$ & Port DC-link capacitances & $50 \mu \mathrm{F}$ \\
\hline$f_{s w}$ & $\begin{array}{l}\text { Synchronized switching } \\
\text { frequency of individual } \\
\text { ports }\end{array}$ & $13.3 \mathrm{kHz}$ \\
\hline
\end{tabular}




\begin{tabular}{ccc}
\hline$N_{12}=N_{13}=N_{14}$ & $\begin{array}{c}\text { Turns ratio of the multiport } \\
\text { transformer (between all } \\
\text { ports) }\end{array}$ & $1: 1$ \\
\hline EV battery type & $\begin{array}{c}\text { Li-Ion, 24 V, } \\
10 \mathrm{Ah}, \\
7 \times 3.7 \mathrm{~V} \\
\text { cells }\end{array}$ \\
& $<100 \mathrm{~W}$ \\
\hline & Max. power flow between \\
different ports & \\
\hline
\end{tabular}

During the experiments, one charging port was regulated to apply $21 \mathrm{~V}$ and another $29.4 \mathrm{~V}$ to the battery terminals (one almost full and another empty). This combination was tested in two different operating modes: simultaneous charging of two batteries with grid supply only and with combined supply from the grid and the solar array.

Figure 5 shows the input voltage and current of port 1 along with voltage $U^{\prime}{ }_{1}$ and current $I_{1}{ }_{1}$ waveforms.

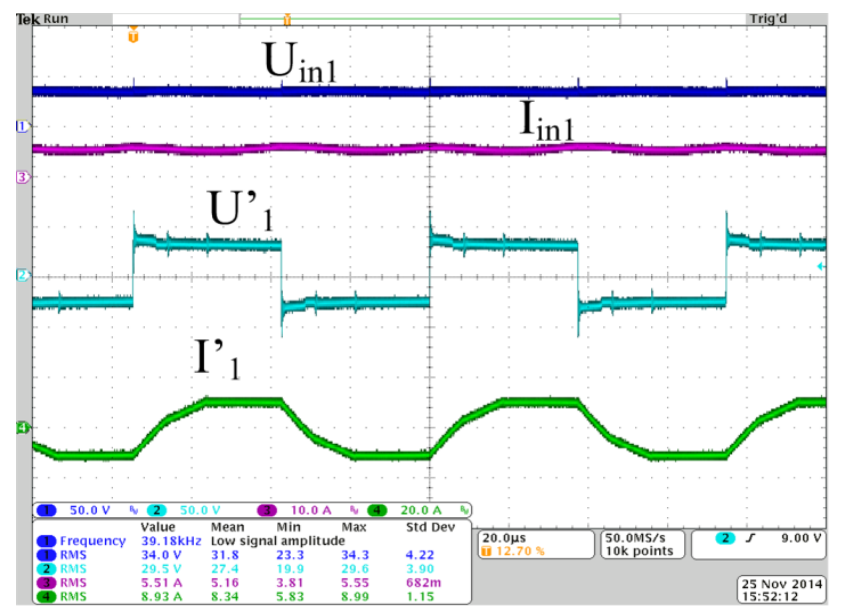

Figure 5. Input and output voltage and current waveforms of port 1.

Output voltage of port 2 was regulated to $29.3 \mathrm{~V}$ that conforms to maximum allowable voltage (Figure 6). Charging current was set to $0.26 \mathrm{C}=2.6 \mathrm{~A}$.

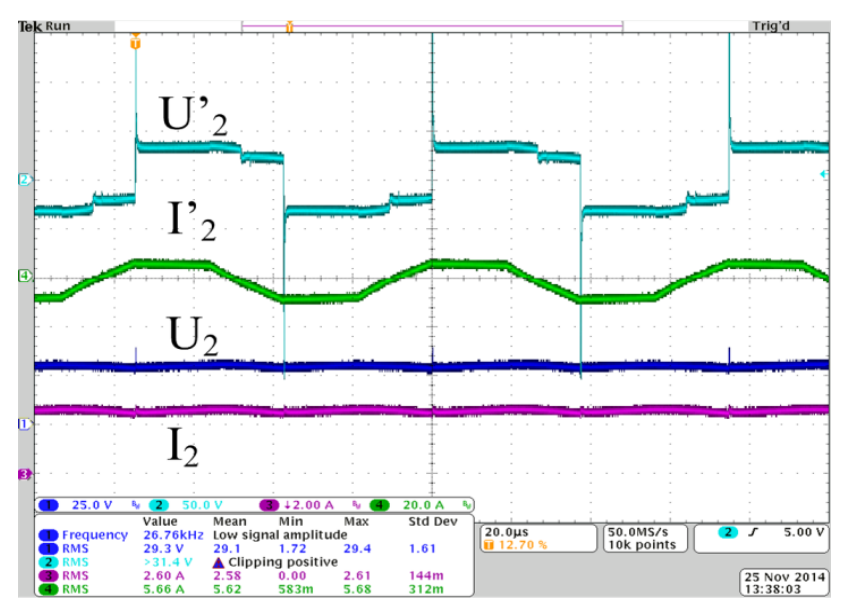

Figure 6. Input and output voltage and current waveforms of port 2.

To regulate the charging voltage, a $1.68 \mathrm{rad}$ (96 deg.) phase shift $\varphi_{12}$ between $U^{\prime}{ }_{1}$ and $U^{\prime}{ }_{2}$ was applied. At the same time, the output voltage of port 3 was regulated to $21.0 \mathrm{~V}$ (Figure 7). Charging current was limited to $1.7 \mathrm{~A}$. To regulate the charging voltage to a required level, a $0.67 \mathrm{rad}$ (38 deg.) phase shift $\varphi_{13}$ between $U_{1}^{\prime}$ and $U_{3}^{\prime}$ was used.

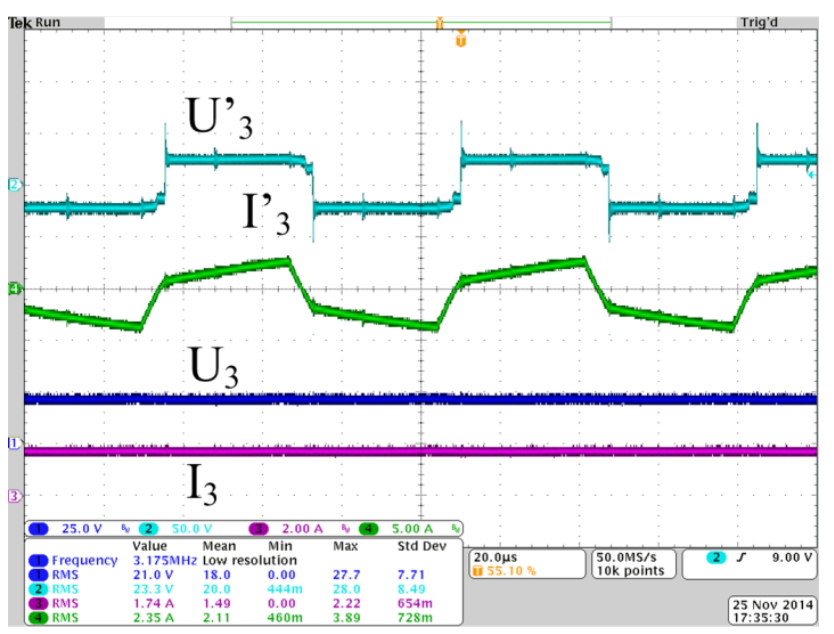

Figure 7. Input and output voltage and current waveforms of port 3.

Voltage waveforms across multiport transformer windings and relevant phase shifts are shown in Figure 8.

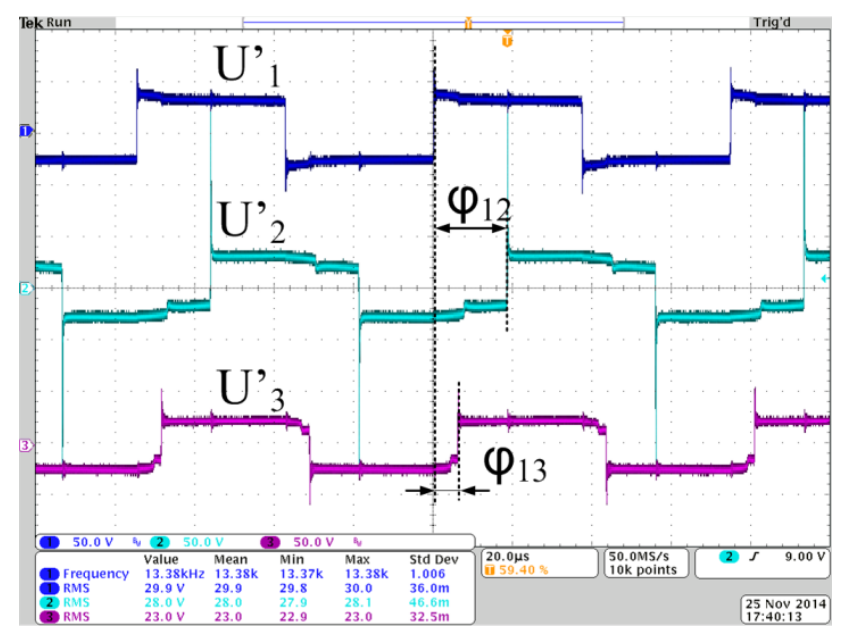

Figure 8. Output voltage waveforms of ports 1,2, and 3.

It can be seen that a multiport converter is able to regulate the output voltages of each port simultaneously. Experiments have shown also that it is not advisable to use large phase angles, as the efficiency of the charger will drop drastically (Figure 1) (although a wide range output voltage regulation is possible like in dual active bridge converters) [8], [9].

Our next experiments demonstrate the multiport converter's ability to be supplied from two different energy sources simultaneously. As the solar array will be able to supply the charger, the energy flow from the grid will be reduced. Output parameters of ports 1 and 2 will be kept the same as in our previous experiment. Input voltage of port 1 is kept at $32 \mathrm{~V}$ and at port 4 the input applied is $41 \mathrm{~V}$ (Figure 9). 


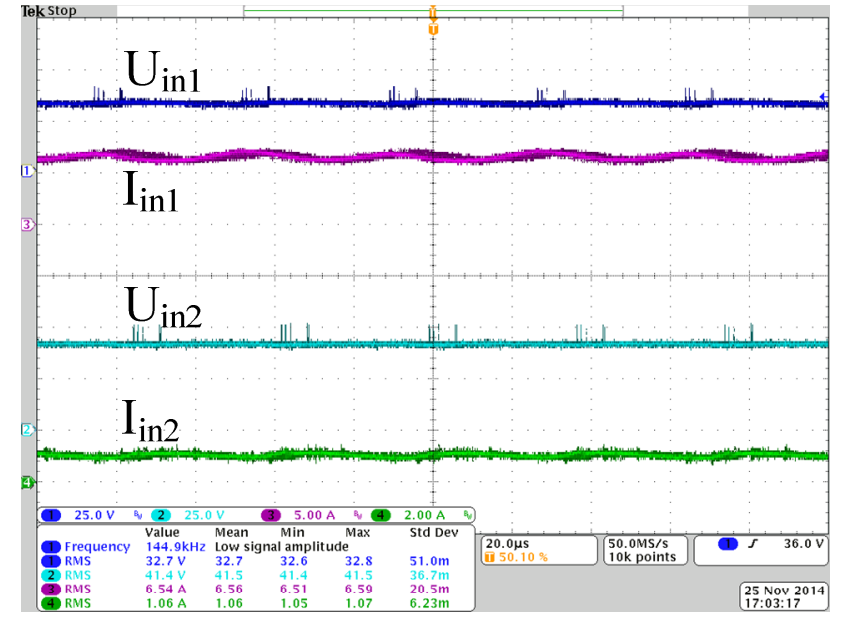

Figure 9. Input voltages and currents of ports 1 and 4 (energy flow from the grid and the renewable energy port.

Input current is shared between ports 1 and 4. Power flow balance between ports 1 and 4 can also be regulated via alternating phase angle $\varphi_{14}$ (Figure 10).

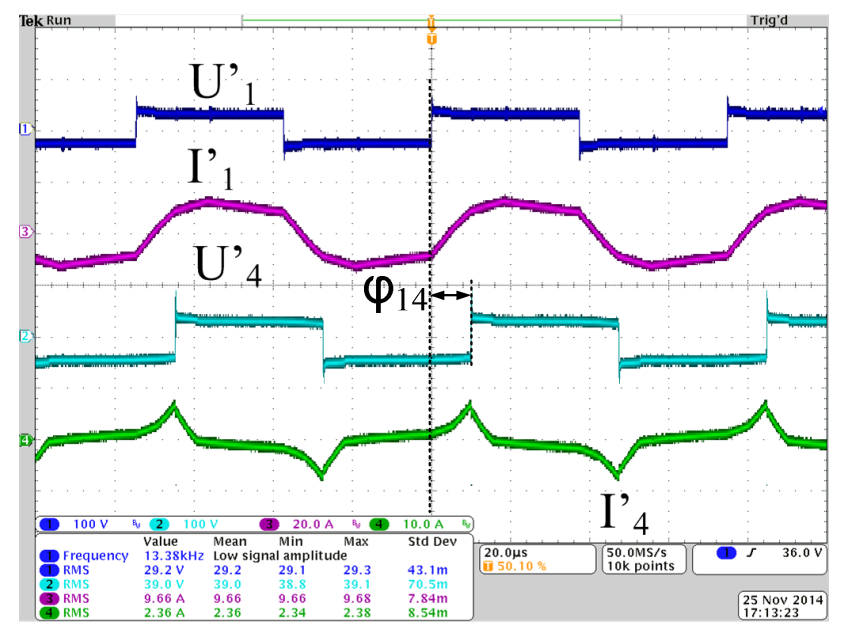

Figure 10. Output voltage and current waveforms of ports 1 and 4 (energy flow from the grid and the renewable energy port).

During the experiment, phase angle $\varphi 14$ was $0.84 \mathrm{rad}$ (48 deg), port 1 shared $76 \%$ and port 2 shared $24 \%$ of the total load. As there is no voltage boost stage used, the energy flow between the solar port and either charging ports will disappear when $U_{4}<U_{2}$ or $U_{4}<U_{3}$.

\section{CONCLUSIONS}

Experimental results show that the multiport topology is suitable for energy flow balancing and battery charging voltage and current regulation for light electric vehicles (electric scooters and motor assisted bicycles). Wide output voltage regulation of a multiport charging converter is not feasible, as the converter's efficiency is directly affected by the phase angle between the control signals of different ports. The maximum battery voltage difference between an empty and a full battery is about $29 \%$ and all phase angles are smaller than $0.84 \mathrm{rad}$. At the input port, a rectified grid voltage can be used as different voltage levels at supply and charging ports can be evened out by the turns ratios of the multiport transformer. Multiport transformers provide also the galvanic isolation between the grid and low voltage charging ports. The use of switching frequency $>10 \mathrm{kHz}$ allows us to build a multiport transformer in compact form.

Despite its limitations, it is advisable to use the multiport topology in EV charging stations when there are multiple charging ports and different input ports and integrated energy storages are used.

\section{ACKNOWLEDGEMENTS}

This research was supported by Estonian Ministry of Education and Research (Project SF0140016s11), Estonian Science Foundation (Grants ETF8687, ETF9350) and Latvian Council of Science (Grant 416/2012).

\section{REFERENCES}

[1] Gunasekaran, D.; Umanand, L. "A multi-winding transformer based power converter topology for a growing DC micro-grid structure", Power Electronics, Drives and Energy Systems (PEDES), 2012 IEEE International Conference on, On page(s): 1 $6,2012$.

[2] Jalakas, T.; Roasto, I.; Vinnikov, D., "Electric vehicle fast charger high voltage input multiport converter topology analysis," Compatibility and Power Electronics (CPE), 2013 8th International Conference, pp.326,331, 5-7 June 2013.

[3] Gunasekaran, D.; Umanand, L., "Integrated magnetics based multiport bidirectional DC-DC converter topology for discontinuousmode operation," Power Electronics, IET, vol.5, no.7, pp.935 944, August 2012.

[4] Waltrich, G.; Duarte, J.L.; Hendrix, M. A M, "Multiport converters for fast chargers of electrical vehicles - Focus on high-frequency coaxial transformers," Power Electronics Conference (IPEC), 2010 International, pp.3151,3157, 21-24 June 2010.

[5] Hussein, H.A.-H.; Batarseh, I., "A Review of Charging Algorithms for Nickel and Lithium Battery Chargers," Vehicular Technology, IEEE Transactions on, vol.60, no.3, pp.830,838, March 2011.

[6] H. Tao, A. Kotsopoulos, J. L. Duarte, and M. A. M. Hendrix, "A Soft-Switched Three-Port Bidirectional Converter for Fuel Cell and Supercapacitor Applications," Power Electronics Specialists Conference, 2005. PESC '05. IEEE 36th, pp: 2487 - 2493, 2005.

[7] Yapa, Ruchira; Forsyth, Andrew, "Extended soft switching operation of the triple active bridge convereter," Power Electronics, Machines and Drives (PEMD 2012), 6th IET International Conference on, pp.1,6, 27-29 March 2012.

[8] F. Krismer, S. Round, and J. W. Kolar, "Performance optimization of a high current dual active bridge with a wide operating voltage range," in 37th IEEE Proc. Power Electron. Spec. Conf., pp. 1-7, 2006.

[9] V. Beldjajev, "Research and development of the new topologies for the isolation stage of the power electronic transformer", TUT Press, 2013 ISBN/ISSN: 9789949234813, 2013. 